\title{
Autocrine action of adipokine omentin-1 in the SW480 colon cancer cell line
}

\author{
YAQIN ZHANG $^{1 *}$, XIAOTONG ZHAO $^{1 *}$ and MINGWEI CHEN ${ }^{1,2}$ \\ ${ }^{1}$ Department of Endocrinology, The First Affiliated Hospital of Anhui Medical University, \\ Hefei, Anhui 230022; ${ }^{2}$ Institute of Traditional Chinese Medicine Diabetes Prevention, \\ Anhui Academy of Traditional Chinese Medicine, Hefei, Anhui 230032, P.R. China
}

Received March 3, 2019; Accepted October 10, 2019

DOI: $10.3892 / \mathrm{ol} .2019 .11131$

\begin{abstract}
Omentin-1, a 34-kDa protein, has been demonstrated to be associated with colorectal cancer (CRC). Epidemiological and clinical studies have indicated that the levels of circulating omentin-1 are significantly increased in patients with CRC, but the cause of the high omentin-1 levels and whether CRC cells express this adipokine have not been determined. In the present study, human colorectal carcinoma and para-carcinoma tissues were collected from 24 patients with CRC. In addition, SW480 and HCT116 colon cancer cells were cultured in vitro. The expression and localization of omentin-1 protein in human CRC and para-carcinoma tissues were determined by immunohistochemistry. The mRNA and protein expression levels of omentin-1 in human CRC and para-carcinoma tissues were detected by reverse transcription-quantitative PCR (RT-qPCR) and western blotting, respectively. In addition, omentin-1 mRNA expression levels in SW480 and HCT116 cell lines were detected by RT-qPCR. Since SW480 cells exhibited higher omentin-1 mRNA levels compared with those of HCT116 cells, SW480 cells were selected for further experiments. The expression of omentin-1 protein in the supernatant and lysate of SW480 cells obtained at 6, 12, 24 and $48 \mathrm{~h}$ was determined by ELISA. The immunohistochemistry results demonstrated that the positive expression of omentin-1 protein was mainly located in the cytoplasm of cancer cells in human CRC tissues. The mRNA and protein expression levels of omentin-1 in the CRC tissues were higher compared with those in para-carcinoma tissues. The expression levels of omentin-1 were detected in the cell lysate and supernatant of SW480 cells; the expression level of omentin-1 protein in the cell lysate was higher compared with that in the supernatant.
\end{abstract}

Correspondence to: Professor Mingwei Chen, Department of Endocrinology, The First Affiliated Hospital of Anhui Medical University, 218 Jixi Road, Hefei, Anhui 230022, P.R. China

E-mail: chmw1@163.com

*Contributed equally

Key words: colorectal cancer, omentin-1, adipocytokine, autocrine
These results indicated that SW480 cells secret and express the adipokine omentin-1 endogenously. Omentin-1 may serve its potential carcinogenetic role in CRC through endocrine, autocrine and paracrine pathways.

\section{Introduction}

The prevalence of obesity has rapidly increased globally in recent years with changing lifestyles and diets. An epidemiological study in 2017, on $\sim 130$ million people aged $>5$ years, demonstrated that obesity rates increased from $<1 \%$ (equivalent to 5 million girls and 6 million boys) to $\sim 6 \%$ in girls (50 million) and $\sim 8 \%$ in boys (74 million) between 1975 and 2016; combined, the number rose by more than tenfold globally (1). Obesity has been associated with a number of malignancies in epidemiological studies on oesophageal, liver, gallbladder, pancreatic, kidney and colorectal cancer (CRC) (2-4), and is considered an important risk factor for cancer (5).

CRC is a common malignant tumour of the digestive system. The incidence rate of CRC has increased year by year, and the cause of the disease has been thoroughly studied; according to data from GLOBOCAN in 2012, there are 1.6 million new cases of CRC and 694,000 people that die from CRC worldwide every year (6). Obesity is associated with $\mathrm{CRC}$, but the pathogenesis of obesity-induced CRC remains unclear (7). Previous studies have suggested that adipokines secreted by the adipose tissue serve an important role in the interaction between obesity (especially abdominal obesity), insulin resistance and CRC (8-10); therefore, adipokines have received increasing attention.

Adipose tissue not only stores excess energy, but also secretes adipokines, which are produced by adipocytes (e.g. resistin, visfatin, leptin and adiponectin) and the stromovascular fraction of adipose tissue cells, such as tumour necrosis factor $\alpha$ (TNF- $\alpha$ ), interleukin-6 (IL-6) and plasminogen activator inhibitor-1. These adipokines affect numerous physiological processes, including thermogenesis, neuroendocrine function, glucose and lipid metabolism, inflammation, appetite, energy balance, reproduction, angiogenesis, cell proliferation and atherosclerosis (11-13). In addition, an association between adipokines and several obesity-related disorders, including cancer, has been demonstrated $(14,15)$. 
Omentin-1 is a $34-\mathrm{kDa}$ protein; its gene, also termed intelectin, was initially cloned in intestinal paneth cells, and was considered to participate in intestinal microbial surveillance (16). Later, omentin-1 was demonstrated to be secreted from human visceral adipose tissue, and was reported as an adipokine that increases adipocyte glucose intake and insulin sensitivity (17). Omentin-1 is associated with metabolic syndromes (such as obesity and insulin resistance) (18), as well as with cardiac function (19), immune response (20) and reproductive diseases (21). Studies have identified a close association between omentin-1 and the development of CRC. Fazeli et al (22) demonstrated that circulating omentin-1 levels were significantly increased in patients with CRC compared with those in healthy subjects independent of obesity. Aleksandrova et al (23) reported that omentin-1 concentration was an independent predictor of CRC risk during a mean follow-up time of 10.4 years. These data suggested that omentin-1 may be implicated in the risk of CRC. However, the cause of the high circulating omentin-1 level in patients with CRC, and whether CRC cells express this adipokine remained to be determined. Our previous study demonstrated that omentin-1 induced the proliferation of CRC cells (24). Thus, the present study aimed to clarify whether CRC cells endogenously secreted and expressed omentin-1, which may act on CRC cells in an autocrine manner.

\section{Materials and methods}

Patient samples and tissue collection. This study was conducted at The First Affiliated Hospital of Anhui Medical University (Hefei, China) between April and December 2014. The study was approved by the Ethics Committee of The First Affiliated Hospital of Anhui Medical University and all procedures performed in studies involving human participants were in accordance with the ethical standards of the institutional and/or national research committee and with the 1964 Helsinki declaration and its later amendments or comparable ethical standards. Informed consent was obtained from all participants. A total of 24 patients (13 males and 11 females; mean age, 55.13 \pm 8.67 years; age range, 30-72 years) with a first diagnosis of histologically confirmed CRC. None of whom had undergone radiotherapy or chemotherapy prior to surgery, were selected for the study. The inclusion criteria were age $\geq 35$ years and body mass index (BMI) between 20 and $25 \mathrm{~kg} / \mathrm{m}^{2}$. The exclusion criteria were previous gastrointestinal tract surgery, familial adenomatous polyposis, previous polypectomy, use of medications that impair glucose tolerance, pregnancy, previous diagnosis of CRC/recurrent patients, previous diagnosis of diabetes, inflammatory bowel disease, serious liver and renal dysfunction, and acute or chronic infectious disease. In addition, intraoperative colon carcinoma tissues and para-carcinoma tissues ( $>5 \mathrm{~cm}$ from cancer tissue) were collected from 24 patients with CRC, in duplicate. One of the duplicate tissues (approximately $2 \times 1 \times 1 \mathrm{~cm}$ ), were stored in a liquid nitrogen tank $\left(-180^{\circ} \mathrm{C}\right)$ and the other was stored in a liquid nitrogen tank fixed in $10 \%$ formalin.

Cell culture and preparation. The human colon epithelial cancer cell lines SW480 and HCT116 were obtained from the Cell Bank of the Chinese Academy of Sciences and were cultured in Dulbecco's modified Eagle's medium (DMEM) supplemented with $10 \%$ foetal bovine serum at $37^{\circ} \mathrm{C}$ with $5 \% \mathrm{CO}_{2}$. The European Collection of Authenticated Cell Cultures PCR technology was used to confirm that the cells were not contaminated with mycoplasma, and cell line authentication was performed by short tandem repeat profiling to exclude misidentified or cross-contaminated cell culture. After the cells reached the logarithmic growth phase (the cell counts in the two cell lines were essentially equal), the total medium was replaced with serum-free medium for $6,12,24$ or $48 \mathrm{~h}$ to avoid the toxic effect of serum on cells and serum-derived contamination and allowed the cells to secrete fresh proteins. To exclude the effect of confluence in cell culture on the expression of omentin-1, the supernatant and lysate of CRC cells were obtained by selecting equal numbers of cells from serum-free cell flasks at 6,12,24 and $48 \mathrm{~h}$. The expression level of omentin-1 in SW480 and HCT116 cell lines was detected by reverse transcription-quantitative PCR (RT-qPCR). Cells that expressed higher mRNA levels of omentin-1, detected by RT-qPCR, were selected for further experiments (25).

Immunohistochemical staining. The tissues (obtained from patients with CRC) were embedded in paraffin, sliced into $4-\mu \mathrm{m}$ sections with a microtome (Leica Instrument Co., Ltd.), dewaxed in the oven $\left(60^{\circ} \mathrm{C}\right.$ overnight) in three incubations with xylene. Subsequently, the sections were placed in 100, 95, 80 and $70 \%$ ethanol for 3-5 min, and placed in distilled water for $3 \mathrm{~min}$ to hydrate (at room temperature). A pressure cooker was used to hold 2.51 double distilled water and $50 \mathrm{ml}$ ethylenediaminetetraacetic acid (EDTA) repair solution ( $\mathrm{pH} \mathrm{8.0)}$ was added and heated to boiling on the induction cooker. Subsequently, the slices were put together with the dyeing rack into the repair solution, fixed (10\% neutral formaldehyde) for $\sim 1 \mathrm{~min}$ and left at room temperature to cool down. The sections were subsequently blocked for endogenous peroxidase activity by $3 \% \mathrm{H}_{2} \mathrm{O}_{2}$ (cat. no. ZLI-9311D; Zsbio) for $20 \mathrm{~min}$ at $37^{\circ} \mathrm{C}$ and washed three times with PBS. An appropriate amount $(\sim 100 \mu 1)$ anti-omentin-1 antibody (cat. no. 11770-1-AP ProteinTech Group, Inc.) was diluted 1:500 and incubated with the specimen for $30 \mathrm{~min}$ at $37^{\circ} \mathrm{C}$, followed by rinsing ( 3 times with $\mathrm{PBS}$ ) and drying the slices. Horseradish peroxidase-labelled goat anti-rabbit secondary antibody (1:10,000; cat. no. TA130003; OriGene Technologies, Inc.) was added to the specimen for $30 \mathrm{~min}$ at $37^{\circ} \mathrm{C}$. 3,3'-Diaminobenzidine colouring solution was added for $\sim 1 \mathrm{~min}$ and rinsed. The colour-developed sections were placed in haematoxylin staining solution for $\sim 3$ min at $37^{\circ} \mathrm{C}$ and washed again. Omentin-1 expression and distribution were observed under an optical microscope (CX43, Olympus; magnification, $x 400$ ). According to manufacturer's instructions, omentin-1 was represented by brown particles in the cytoplasm. The average optical density value (four fields analyzed per section) was calculated by ImagePro Plus 6.0 (Wuhan Gene Beauty Ltd.) to quantitatively compare the difference between the protein expressed by the positive cells in cancerous and adjacent tissues.

Reverse transcription-quantitative PCR (RT-qPCR). The mRNA expression of omentin-1 was measured by RT-qPCR. Total RNA was extracted from ground tissue material 
(24 patients with CRC) using $1 \mathrm{ml}$ TRIzol ${ }^{\circledR}$ (Invitrogen; Thermo Fisher Scientific, Inc.) per $100 \mathrm{mg}$ tissue. In addition, total RNA was extracted from SW480 and HCT116 cells with TRIzol $^{\circledR}$, and cell lysates of SW480 cells and HCT-116 cells were obtained after $6,12,24$ and $48 \mathrm{~h}$ of culture. Next, $0.2 \mathrm{ml}$ chloroform was added, followed by centrifugation at $12,000 \mathrm{xg}$ for $15 \mathrm{~min}$ at $4^{\circ} \mathrm{C}$. Total RNA was precipitated from the mixture in a sterile RNase-free tube by adding $0.5 \mathrm{ml}$ isopropyl alcohol and incubating for $10 \mathrm{~min}$ at $24^{\circ} \mathrm{C}$. The pellet, containing total RNA, was washed with $75 \%$ ethanol and centrifuged at $12,000 \mathrm{x} \mathrm{g}$ for $10 \mathrm{~min}$ at $4^{\circ} \mathrm{C}$. Complementary DNA (cDNA) was synthesised using $2 \mu \mathrm{g}$ total RNA and a cDNA synthesis kit (HiScript ${ }^{\circledR}$ II Reverse Transcriptase; cat. no. R233-01; Thermo Fisher Scientific, Inc.) according to the manufacturer's instructions. The resulting cDNA samples were subjected to PCR analysis using specific primer sets. PCR was performed in tubes containing $1 \mu \mathrm{g}$ cDNA, $5 \mu \mathrm{l} \mathrm{SYBR}{ }^{\circledR}$ Green Master Mix, $1 \mu \mathrm{l}$ each of forward and reverse primers $(10 \mu \mathrm{M})$ and $2 \mu \mathrm{l}$ deionized water to obtain a final volume of $10 \mu \mathrm{l}$. Primers (Table I) were designed by AlleleID 6.0 software (Wuhan Gene Beauty Ltd.) based on the omentin-1 gene sequences indicated in the GenBank online resource (https://www.ncbi. nlm.nih.gov/nucleotide/NM_017625.2?report=genbank\&log $\$=$ nuclalign\&blast_rank=1\&RID=UAJGH89U014). PCR amplification was performed using a PCR thermocycler (Thermo Fisher Scientific, Inc.) under the following conditions: Initial denaturation at $95^{\circ} \mathrm{C}$ for $5 \mathrm{~min}$, followed by 40 cycles of $95^{\circ} \mathrm{C}$ for $5 \mathrm{sec}, 60^{\circ} \mathrm{C}$ for $10 \mathrm{sec}$ and $72^{\circ} \mathrm{C}$ for $20 \mathrm{sec}$.

Relative expression of the studied genes was determined using the $2^{-\Delta \Delta C q}$ method (26), and the data were normalized to $\beta$-actin. All the experiments were conducted in duplicate, and the relative expression of genes was determined in comparison with the expression of the $\beta$-actin gene as a control.

Western blotting. Total protein was isolated from ground tissue samples using radioimmunoprecipitation assay (RIPA; Biyuntian Institute of Biotechnology) buffer. Briefly, $100 \mathrm{mg}$ each sample was mechanically pulverised and resuspended (100 mg tissue/ml) in $1 \mathrm{ml}$ RIPA buffer. Resuspended samples were sonicated for $3 \mathrm{sec}$, repeated 3 times with 10 -sec intervals, on ice, and the insoluble material was removed by centrifugation at $12,000 \mathrm{x} \mathrm{g}$ for $10 \mathrm{~min}$ at $4^{\circ} \mathrm{C}$, while the supernatant was preserved. The concentration of the protein samples was determined by BCA assay and were separated by SDS-PAGE on a $10 \%$ gel (10 $\mu \mathrm{g}$ per lane) and transferred to nitrocellulose membranes. Following blocking in 5\% non-fat milk in Tris-buffered saline containing $0.05 \%$ Tween-20 (TBS-T) for $2 \mathrm{~h}$ at $37^{\circ} \mathrm{C}$, membranes were incubated with a primary antibody against omentin-1 (1:500; cat. no. 11770-1-AP; ProteinTech Group, Inc.) for $1 \mathrm{~h}$ at room temperature and subsequently with an anti-mouse secondary antibody conjugated to horseradish peroxidase $(1: 10,000$; cat. no. TA130003; OriGene Technologies, Inc.) for $0.5 \mathrm{~h}$ at room temperature. Antibody detection was performed by ECL (Thermo Fisher Scientific, Inc.).

ELISA. The expression of omentin-1 protein was measured by the Omentin-1 ELISA kit (Yuanye). Based on a quantitative sandwich enzyme immunoassay technique with a sensitivity of $0.1 \mathrm{ng} / \mathrm{ml}$, the inter-assay and intra-assay coefficient of variation was $<15 \%$. The supernatant and lysate of SW480 cells were obtained following 6, 12, 24 and $48 \mathrm{~h}$ of culture. The optical density of the standards, controls and samples was assessed at a wavelength of $450 \mathrm{~nm}$ by a microplate reader (Bio Tek Instruments, Inc.). Triplicate measurements were performed in a single experiment, and the results were determined by comparing the optical density of the samples to that of the standard curve.

Statistical analysis. The SPSS statistical software package for Windows version 17.0 (SPSS, Inc.) was used for all statistical analyses. Data are expressed as the mean $\pm \mathrm{SD}$. The paired t-test was used to compare the protein and mRNA expression levels of omentin-1 between carcinoma and para-carcinoma tissues. The independent Student's t-test was used to compare the mRNA expression of omentin-1 between SW480 and HCT116 cells. The independent Student's t-test and the one-way analysis of variance (ANOVA) was used to compare the protein and mRNA expression levels of omentin-1 in the supernatant and lysate of SW480 cells at different times, and the Student-Newman-Keuls (SNK-q) test was used for post hoc analysis. $\mathrm{P}<0.05$ was considered to indicate a statistically significant difference.

\section{Results}

Expression of omentin-1 protein in human CRC and para-carcinoma tissues. Immunohistochemical staining of cancer tissue sections under optical microscopy revealed that the omentin-1 protein exhibited brownish-yellow staining in the cytoplasm of cancer cells and the intercellular substance. Weak expression was also observed in normal colonic epithelial cells in para-carcinoma tissues (Fig. 1). The mean optical density of the selected field of view of each slice was further calculated by immunohistochemical image analysis software; the results demonstrated that the expression of omentin-1 protein in human CRC tissues was higher compared with that of para-carcinoma tissues $(0.621 \pm 0.102$ vs. $0.295 \pm 0.030 ; \mathrm{P}<0.01)$.

Omentin-1 mRNA and protein expression levels in human CRC and para-carcinoma tissues. The mRNA (Fig. 2A) and protein (Fig. 2B) levels of omentin-1 determined by RT-qPCR and western blotting, respectively, were significantly higher in human colon carcinoma tissues compared with those in para-carcinoma tissues, and the difference was statistically significant (mRNA, $5.38 \pm 1.25$ vs. $0.98 \pm 0.11 ; \mathrm{P}<0.01$; protein, $1.08 \pm 0.24$ vs. $0.61 \pm 0.06 ; \mathrm{P}<0.01)$.

Comparison of the omentin-1 mRNA expression between SW480 cells and HCT116 cells at different times. SW480 and HCT116 CRC cells secreted omentin-1 mRNA in a time-dependent manner $(\mathrm{P}<0.05)$. In addition, the expression of omentin-1 mRNA in was higher in SW480 cells compared with that in HCT116 cells at 12, 24 and $48 \mathrm{~h}$, however, the difference was not statistically significant (Fig. 3). Therefore, SW480 cells were selected for the following experiment.

Omentin-1 protein expression in the supernatant and lysate of SW480 cells. The ELISA results demonstrated that the supernatant of SW480 cells contained 31.99, 33.40, 
Table I. Target genes and their primer sequences.

\begin{tabular}{llr}
\hline Gene & \multicolumn{1}{c}{ Primer sequence $\left(5^{\prime} \rightarrow 3^{\prime}\right)$} & Product size $(\mathrm{bp})$ \\
\hline Human omentin-1 & F: AGGAAAGTGCAGCTGAGACT & 138 \\
Human $\beta$-actin & R: GGAGACGAAGAACAGGTCCA & 180 \\
& F: GGGAAATCGTGCGTGACATTAAGG & R: CAGGAAGGAAGGCTGGAAGAGTG
\end{tabular}

F, forward; R, reverse.
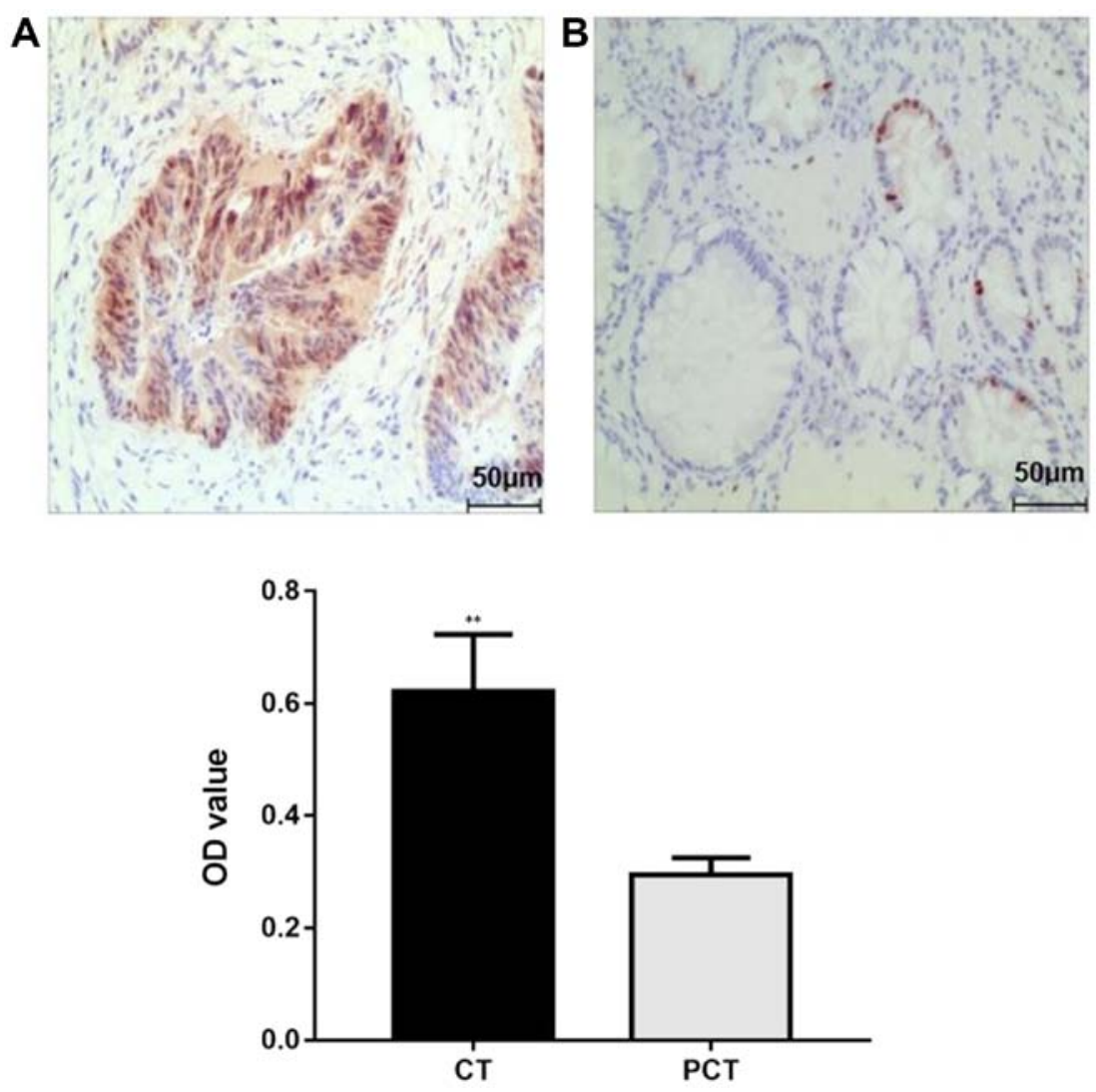

Figure 1. Omentin-1 expression in colorectal cancer tissue determined by immunohistochemistry. Omentin-1 protein expression in (A) carcinoma and (B) para-carcinoma tissues. Magnification, x400. Omentin-1 protein was mainly located in the cytoplasm of cancer cells and the intercellular substance in human colorectal tumour tissues; low expression of omentin-1 was observed in normal colon epithelial cells. The mean optical density of colorectal cancer tissue sections was higher compared with that of the para-cancerous tissues. ${ }^{* *} \mathrm{P}<0.01$. OD, optical density; CT, carcinoma tissues; PCT, para-carcinoma tissues.

38.16 and $48.10 \mathrm{ng} / \mathrm{ml}$ omentin- 1 protein at $6,12,24$ and $48 \mathrm{~h}$, respectively. The lysate of SW480 cells contained 36.88, 43.76, 45.86 and $49.87 \mathrm{ng} / \mathrm{ml}$ omentin- 1 protein at $6,12,24$ and $48 \mathrm{~h}$, respectively. The concentration of omentin-1 was higher in the cell lysates compared with that in the supernatants and the difference is statistically significant at 6,12 and $24 \mathrm{~h}$. Moreover, the secretion of omentin-1 in the cell lysates and the supernatants increased over time (Fig. 4).

\section{Discussion}

Adipose tissue is not only a depot of energy, but also an active endocrine organ, which directly or indirectly affects the pathogenesis of obesity-related disorders through generating large quantities of bioactive proteins termed adipokines or adipocytokines (27). Adipokines are crucial to insulin resistance, regulation of local and systemic inflammation, and associated metabolic complications in a paracrine or endocrine manner. Previous studies have identified associations between cancer biology and certain adipokines $(5,11,28)$.

Omentin-1 may promote tumour proliferation or apoptosis depending on the type of cancer cells. A previous study has demonstrated that omentin-1 promotes human hepatocellular carcinoma apoptosis in vitro via activation of the JNK signalling pathway and p53 up-regulation (29). Another study has demonstrated that the loss of omentin-1 may be involved in obesity-related carcinogenesis (30). By contrast, Uyeturk et al (31) reported a moderate negative correlation between omentin-1 and BMI in patients with benign prostatic hyperplasia; conversely, circulating omentin-1 levels were 
A

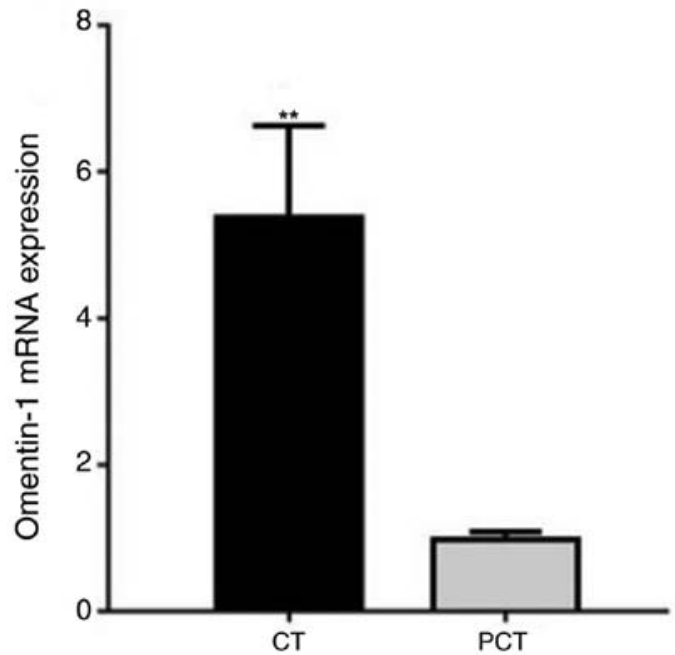

B

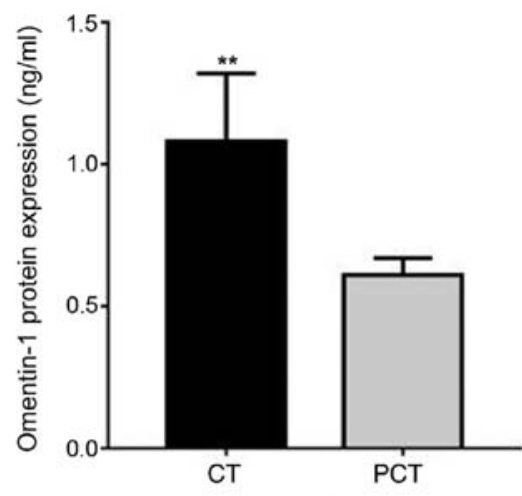

B1 A1 B2 A2 B3 A3

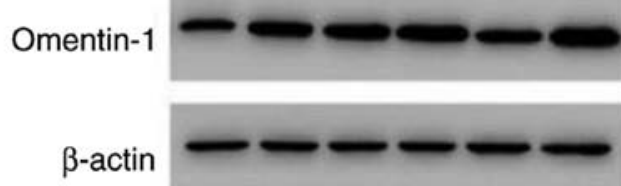

Figure 2. Omentin-1 mRNA and protein expression in colorectal cancer. (A) Comparison of the mRNA expression of omentin-1 between carcinoma and para-carcinoma tissues. The mRNA expression of omentin-1 in colorectal carcinoma tissues was higher compared with that in para-carcinoma tissues. (B) Representative images of western blots. ${ }^{* *} \mathrm{P}<0.01$. CT, carcinoma tissues; PCT, para-carcinoma tissues; A1-3, carcinoma samples; B1-3, para-carcinoma samples. The blots presented are representative samples of this experiment.

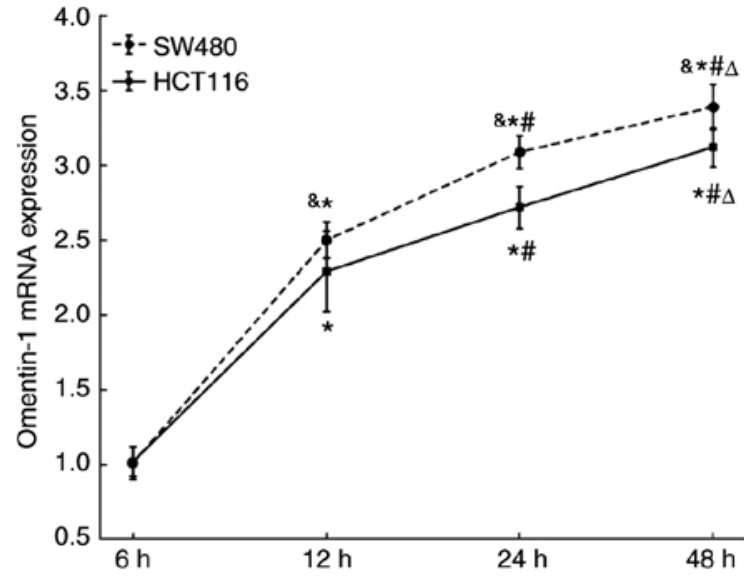

Figure 3. mRNA expression of omentin-1 in the colorectal cancer cell lines SW480 cells and HCT116. The expression level of omentin-1 mRNA in SW480 cells was higher compared with that in HCT116 cells at different time points, however, the difference was not statistically significant. ${ }^{\&} \mathrm{P}>0.05$ vs. HCT116 cells; ${ }^{*} \mathrm{P}<0.05$ vs. $6 \mathrm{~h} ;{ }^{\#} \mathrm{P}<0.05$ vs. $12 \mathrm{~h} ;{ }^{\Delta} \mathrm{P}<0.05$ vs. $24 \mathrm{~h}$.

elevated in patients with prostate cancer. These results may reflect the pathological and 'Janus-faced' biological characteristics of omentin-1 in different types of cancer (32). Therefore, the aim of the present study was to explore positive or negative outcomes in patients with CRC.

As we know, the expression of omentin-1 is inversely correlated with obesity (33), and obesity is a risk factor for CRC; therefore, it is speculated that the expression of omentin-1 in patients with obesity and at risk of CRC should be low. However, Aleksandrova et al (23) demonstrated in a prospective cohort study that omentin-1 concentration was positively correlated with the risk of CRC, similar to the results of Fazeli et al (22). A previous study also reported this

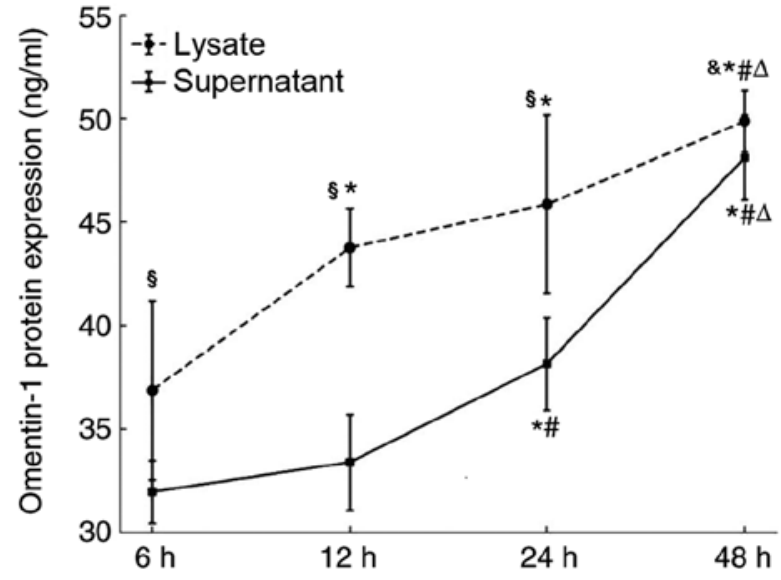

Figure 4. The expression of omentin-1 protein in the supernatant and lysate of SW480 cells at different times. The expression level of omentin-1 protein in the cell lysate was higher compared with that in the supernatant and the difference was statistically significant at 6,12 and $24 \mathrm{~h}$. The expression was time-dependent in the lysate and the supernatant. ${ }^{\&} \mathrm{P}>0.05$ vs. supernatant; ${ }^{\S} \mathrm{P}<0.05$ vs. supernatant; ${ }^{*} \mathrm{P}<0.05$ vs. 6 h; ${ }^{\#} \mathrm{P}<0.05$ vs. $12 \mathrm{~h} ;{ }^{\Delta} \mathrm{P}<0.05$ vs. 24 h.

contradiction: The expression of omentin-1 was decreased in patients with obesity compared with that in healthy subjects; the risk of CRC was increased in patients with obesity; and omentin-1 promoted the proliferation of colon cancer cells (24). This suggested that, in addition to human visceral adipose tissue, omentin- 1 may be secreted by other cells, at least in patients with CRC. A previous study suggested that the colon cancer cell line HCT116 did not produce resistin in $\mathrm{CRC}$ and that other cells that secrete this adipokine may be present in the cancer stroma; however, the concentration of visfatin was greater in the cell lysate compared with that in the supernatant, and the secretion of this adipokine was increased over time (34). These results demonstrated that HCT116 cells 
endogenously secreted and expressed visfatin. Therefore, it is speculated that the colon cancer cell lines SW480 and HCT116 can also secrete autocrine omentin-1. The immunohistochemical experiments in the present study demonstrated that the expression of omentin-1 protein was mainly located in the cytoplasm and interstitial CRC cells. Further analysis revealed that the protein and mRNA levels of omentin-1 in human CRC tissues of 24 patients were significantly higher compared with those of the para-carcinoma tissues. To test this hypothesis, human SW480 and HCT116 CRC cells were cultured and the results indicated that SW480 and HCT11 expressed omentin-1, and SW480 cells exhibited higher expression levels of omentin-1 mRNA compared with those of HCT116 cells, however, with no statistical significance. Thus, SW480 was selected as the cell line for subsequent studies. The study found that the concentration of omentin-1 was higher in the cell lysates compared with that in the supernatants with statistical significance at 6,12 and $24 \mathrm{~h}$. Moreover, the secretion of omentin-1 in the cell lysates and supernatants increased over time. These results revealed that SW480 cells could endogenously secrete and express omentin-1. A previous study demonstrated that omentin-1 induced the proliferation of colon cancer SW480 cells (24); similarly, omentin-1 gene silencing may inhibit the proliferation and promote the apoptosis of human SW480 cells (35). The present study further demonstrated that the CRC cell line SW480 may secrete this adipokine. Therefore, based on the above results, omentin-1 may act on CRC cells in an autocrine manner.

A previous study has demonstrated that omentin-1 increased glucose intake through stimulating insulin production in subcutaneous and omental human adipocytes (17). Conversely, insulin and glucose dose-dependently decreased omentin-1 mRNA and protein expression, as well as secretion (36). In clinical studies, omentin-1 levels were decreased in patients with type 2 diabetes compared with those of normal subjects (37) and obesity compared with those of lean subjects (38). Therefore, omentin-1 levels are considered to be an indicator of the metabolic consequences or co-morbidities associated with obesity (39). It is unclear whether high omentin-1 expression is associated with positive or negative outcomes in patients with different diseases. Shibata et al (40) reported that circulating omentin-1 levels exhibited a negative correlation with carotid intima-media thickness in apparently healthy Japanese men. Greulich et al (41) identified omentin-1 as a cardioprotective adipokine, and demonstrated that cardiovascular dysfunction in type 2 diabetes may be due to a decline in omentin-1 levels. In addition, omentin-1 inhibits TNF- $\alpha$-induced vascular inflammation in human endothelial cells (42). Similarly, in vascular smooth muscle cells, omentin-1 inhibits TNF- $\alpha$-induced vascular cell adhesion molecule-1 expression (43). Circulating omentin-1 concentration negatively correlates with C-reactive protein in subjects with normal and impaired glucose tolerance (44). These results suggest an anti-inflammatory role of omentin-1, and provide a different perspective on the role of adipokines in chronic inflammation, as well as in the occurrence and progression of colon cancer. To further understand the effects of different adipokines in cancer progression, further studies are needed.

The present study had several limitations. Firstly, unneglectable variations exist between different CRC cell lines, presented by highly variable gene expression, proliferation and metastatic potential, which results in clinically heterogeneous cancer development. To simplify the analysis, only two cell lines were examined in the present study. Furthermore, the present study did not explore the role of inflammation or immune cells in omentin-1 expression in cancerous tissues. To determine whether CRC cells exhibit variable omentin-1 expression abilities, further in vivo experiments focusing on $\mathrm{CRC}$ are required.

In conclusion, omentin-1 protein was demonstrated to be synthesized by colon epithelial cancer cells, and omentin-1 affected SW480 CRC cells in an autocrine and endocrine (produced by adipocytes) manner. Therefore, the novel adipokine omentin-1 may serve an important role in the therapeutic strategy for CRC.

\section{Acknowledgements}

Not applicable.

\section{Funding}

The present study was supported by the Natural Science Foundation of Anhui (grant. no. 1508085MH150).

\section{Availability of data and materials}

The datasets used and/or analyzed during the current study are available from the corresponding author on reasonable request.

\section{Authors' contributions}

$\mathrm{YZ}$ and $\mathrm{XZ}$ designed the study, collected the samples and materials, analysed the data and wrote the manuscript. MC designed the study and analysed the data with $\mathrm{YZ}$ and XZ. All authors approved the final version of the manuscript.

\section{Ethics approval and consent to participate}

The present study was approved by the Ethics Committee of The First Affiliated Hospital of Anhui Medical University. Informed consent was obtained from each patient.

\section{Patient consent for publication}

Not applicable.

\section{Competing interests}

The authors declare that they have no competing interests.

\section{References}

1. NCD Risk Factor Collaboration (NCD-RisC): Worldwide trends in body-mass index, underweight, overweight, and obesity from 1975 to 2016: A pooled analysis of 2416 population-based measurement studies in 128.9 million children, adolescents, and adults. Lancet 390: 2627-2642, 2017.

2. Iyengar NM, Morris PG, Hudis CA and Dannenberg AJ: Obesity, inflammation, and breast cancer. In: Obesity, Inflammation and Cancer. Dannenberg A, Berger N (eds). Springer New York, NY, pp181-217, 2013. 
3. Yoon HH, Lewis MA, Shi Q, Khan M, Cassivi SD, Diasio RB and Sinicrope FA: Prognostic impact of body mass index stratified by smoking status in patients with esophageal adenocarcinoma. J Clin Oncol 29: 4561-4567, 2011.

4. Iyengar NM, Hudis CA and Dannenberg AJ: Obesity and inflammation: New insights into breast cancer development and progression. Am Soc Clin Oncol Educ Book 33: 46-51, 2013.

5. van Kruijsdijk RC, van der Wall E and Visseren FL: Obesity and cancer: The role of dysfunctional adipose tissue. Cancer Epidemiol Biomarkers Prev 18: 2569-2578, 2009.

6. Ferlay J, Soerjomataram I, Dikshit R, Eser S, Mathers C, Rebelo M, Parkin DM, Forman D and Bray F: Cancer incidence and mortality worldwide: Sources, methods and major patterns in GLOBOCAN 2012. Int J Cancer 136: E359-E386, 2015.

7. Durko L and Malecka-Panas E: Lifestyle modifications and colorectal cancer. Curr Colorectal Cancer Rep 10: 45-54, 2014.

8. Yamaji T, Iwasaki M, Sasazuki S and Tsugane S: Interaction between adiponectin and leptin Influences the risk of colorectal adenoma. Cancer Res 70: 5430-5437, 2010.

9. Otake S, Takeda H, Fujishima S, Fukui T, Orii T, Sato T, Sasaki Y, Nishise S and Kawata S: Decreased levels of plasma adiponectin associated with increased risk of colorectal cancer World J Gastroenterol 16: 1252-1257, 2010.

10. Kumor A, Daniel P, Pietruczuk M and Malecka-Panas E: Serum leptin, adiponectin, and resistin concentration in colorectal adenoma and carcinoma (CC) patients. Int J Colorectal Dis 24 275-281, 2009

11. Nowakowska-Zajdel E, Wierzchowiec O, Kokot T, Fatygaa E and Muc-Wierzgon M: Metabolic abnormalities in colorectal cancer patients. J Endocrinol Metab 2: 135-138, 2012.

12. Halberg N, Wernstedt-Asterholm I and Scherer PE: The adipocyte as an endocrine cell. Endocrinol Metab Clin North Am 37: 753-768, 2008

13. Trujillo ME and Scherer PE: Adipose tissue-derived factors: Impact on health and disease. Endocr Rev 27: 762-789, 2006

14. Paz-Filho G, Lim EL, Wong ML and Licinio J: Associations between adipokines and obesity-related cancer. Front Biosci (Landmark Ed) 16: 1634-1650, 2011

15. Balistreri CR, Caruso C and Candore G: The role of adipose tissue and adipokines in obesity-related inflammatory diseases Mediators Inflamm 2010: 802078, 2010.

16. Wrackmeyer U, Hansen GH, Seya T and Danielsen EM: Intelectin: A novel lipid raft-associated protein in the enterocyte brush border. Biochemistry 45: 9188-9197, 2006.

17. Yang RZ, Lee MJ, Hu H, Pray J, Wu HB, Hansen BC, Shuldiner AR, Fried SK, McLenithan JC and Gong DW: Identification of omentin as a novel depot-specific adipokine in human adipose tissue: Possible role in modulating insulin action. Am J Physiol Endocrinol Metab 290: E1253-E1261, 2006.

18. Sepandar F, Rashidbeygi E, Maghbooli Z, Khorrami-Nezhad L, Hajizadehoghaz $M$ and Mirzaei K: The association between resting metabolic rate and metabolic syndrome May Be mediated by adipokines in overweight and obese women. Diabetes Metab Syndr 13: 530-534, 2019.

19. Li F, Pang LZ, Zhang L, Zhang Y, Zhang YY, Yu BY and Kou JP: YiQiFuMai powder injection ameliorates chronic heart failure through cross-talk between adipose tissue and cardiomyocytes via up-regulation of circulating adipokine omentin. Biomed Pharmacother 119: 109418, 2019.

20. Zabetian-Targhi F, Mirzaei K, Keshavarz SA and Hossein-Nezhad A: Modulatory Role of omentin-1 in inflammation: Cytokines and dietary intake. J Am Coll Nutr 35: 670-678, 2016.

21. Briana DD and Malamitsi-Puchner A: Intrauterine growth restriction: The controversial role of perinatal adipocytokines in the prediction of metabolic adult disease. J Matern Fetal Neonatal Med: 1-6, 2019 Sept 25, 2019 (Epub ahead of print). doi: 10.1080/14767058.2019.1669556. ).

22. Fazeli MS, Dashti H, Akbarzadeh S, Assadi M, Aminian A, Keramati MR and Nabipour I: Circulating levels of novel adipocytokines in patients with colorectal cancer. Cytokine 62: 81-85, 2013.

23. Aleksandrova K, di Giuseppe R, Isermann B, Biemann R, Schulze M, Wittenbecher C, Fritsche A, Lehmann R, Menzel J, Weikert C, et al: Circulating omentin as a novel biomarker for colorectal cancer risk: Data from the EPIC-Potsdam cohort study. Cancer Res 76: 3862-3871, 2016.
24. Yan C, Xiaotong Zhao and Mingwei C: A study on relationship of adipokine omentin-1 involved in colorectal cancer. Acta Univ Med Anhui 1: 75-78, 2015.

25. Qin Y, Huo ZB, Song X, Chen X, Tian X and Wang X: mir-106a regulates cell proliferation and apoptosis of colon cancer cells through targeting the PTEN/PI3K/AKT signaling pathway. Oncol Lett 15: 3197-3201, 2018

26. Livak KJ and Schmittgen TD: Analysis of relative gene expression data using real-time quantitative PCR and the 2(-Delta Delta (T)) method. Methods 25: 402-408, 2001.

27. Booth A, Magnuson A, Fouts J and Foster M: Adipose tissue, obesity and adipokines: Role in cancer promotion. Horm Mol Biol Clin Investig 21: 57-74, 2015.

28. Yang G, Fan W, Luo B, Xu Z, Wang P, Tang S, Xu P and Yu M: Circulating resistin levels and risk of colorectal cancer: A Meta-analysis. Biomed Res Int 2016: 7367485, 2016.

29. Zhang YY and Zhou LM: Omentin-1, a new adipokine, promotes apoptosis through regulating Sirt1-dependent p53 deacetylation in hepatocellular carcinoma cells. Eur J Pharmacol 698: 137-144, 2013.

30. Washimi K, Yokose T, Yamashita M, Kageyama T, Suzuki K, Yoshihara M, Miyagi Y, Hayashi H and Tsuji S: Specific expression of human intelectin-1 in malignant pleural mesothelioma and gastrointestinal goblet cells. PLoS One 7: 39889, 2012.

31. Uyeturk U, Sarıci H, Kın Tekce B, Eroglu M, Kemahl E, Uyeturk $U$ and Gucuk A: Serum omentin level in patients with prostate cancer. Med Oncol 31: 923, 2014

32. Kawashima K, Maeda K, Saigo C, Kito Y, Yoshida K and Takeuchi T: Adiponectin and intelectin-1: Important adipokine players in obesity-related colorectal Carcinogenesis. Int J Mol Sci 18: pii: E866, 2017.

33. Jaikanth C, Gurumurthy P, Cherian KM and Indhumathi T: Emergence of omentin as a pleiotropic adipocytokine. Exp Clin Endocrinol Diabetes 121: 377-383, 2013.

34. Ghaemmaghami S, Mohaddes SM, Hedayati M, Gorgian Mohammadi M and Dehbashi G: Resistin and visfatin expression in HCT-116 colorectal cancer cell line. Int J Mol Cell Med 2: 143-150, 2012.

35. Li XT, Wan LJ, Zhang QH, Chen MW, Xia TJ, Xu M and Tang SG: Effects of omentin-1 gene silence on proliferation and apoptosis of colon cancer cells. Acta Univ Med Anhui 54: 60-63, 2019.

36. Tan BK, Adya R, Farhatullah S, Lewandowski KC, O'Hare P, Lehnert $\mathrm{H}$ and Randeva HS: Omentin-1, a novel adipokine, is decreased in overweight insulin-resistant women with polycystic ovary syndrome: Ex vivo and in vivo regulation of omentin-1 by insulin and glucose. Diabetes 57: 801-808, 2008

37. Pan HY, Guo L and Li Q: Changes of serum omentin-1levels in normal subjects and in patients with impaired glucose regulation and with newly diagnosed and untreated type 2 diabetes. Diabetes Res Clin Pract 88: 29-33, 2010.

38. de Souza Batista CM, Yang RZ, Lee MJ, Glynn NM, Yu DZ, Pray J, Ndubuizu K, Patil S, Schwartz A, Kligman M, et al: Omentin plasma levels and gene expression are decreased in obesity. Diabetes 56: 1655-1661, 2007.

39. Tan BK, Adya R and Randeva HS: Omentin: A novel link between inflammation, diabesity, and cardiovascular disease. Trends Cardiovasc Med 20: 143-148, 2010.

40. Shibata R, Takahashi R, Kataoka Y, Ohashi K, Ikeda N, Kihara S, Murohara T and Ouchi N: Association of fat-derived plasma protein omentin with carotid artery intima-media thickness in apparently healthy men. Hypertens Res 34: 1309-1312, 2011.

41. Greulich S, Chen WJ, Maxhera B, Rijzewijk LJ, van der Meer RW, Jonker JT, Mueller H, de Wiza DH, Floerke RR, Smiris K, et al: Cardioprotective properties of omentin-1 in type 2 diabetes: Evidence from clinical and in vitro studies. PLoS One 8: e59679, 2013.

42. Yamawaki H, Kuramoto J, Kameshima S, Usui T, Okada M and Hara Y: Omentin, a novel adipocytokine inhibits TNF-induced vascular inflammation in human endothelial cells. Biochem Biophys Res Commun 408: 339-343, 2011.

43. Kazama K, Usui T, Okada M, Hara Y and Yamawaki H: Omentin plays an anti-inflammatory role through inhibition of TNF- $\alpha$-induced superoxide production in vascular smooth muscle cells. Eur J Pharmacol 686: 116-123, 2012.

44. Moreno-Navarrete JM, Ortega F, Castro A, Sabater M, Ricart W and Fernández-Real JM: Circulating omentin as a novel biomarker of endothelial dysfunction. Obesity (Silver Spring) 19 $1552-1559,2011$.

This work is licensed under a Creative Commons Attribution-NonCommercial-NoDerivatives 4.0 International (CC BY-NC-ND 4.0) License. 